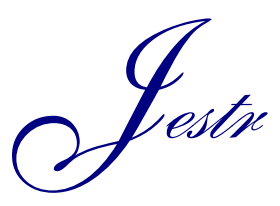

\title{
Study of the effect of machining parameters on material removal rate and electrode wear during Electric Discharge Machining of mild steel
}

\author{
A. Majumder \\ National Institute Technology, Agartala, Tripura West, Tripura, India.
}

Received 30 March 2011; Accepted 3 February 2012

\begin{abstract}
Electric Discharge Machining (EDM) is one of the most popular non-conventional machining processes. During Electric Discharge Machining (EDM) the process parameters plays a very important role in deciding the material removal rate (MRR) and electrode wear (EW). In the present investigation mild steel specimens have been machined by using Electric Discharge Machining (EDM). The material removal rate (MRR) and electrode wear (EW) ,thus, measured have been correlated with the machining parameters such as, spark current, pulse on time and pulse off time by the use of response surface methodology (RSM). The equations, thus, derived have been used to find out the effect of machining parameters on the material removal rate (MRR) and electrode wear (EW) during Electric Discharge Machining (EDM) process.
\end{abstract}

Keywords: Material removal rate, Electrode wear; Supply current; Pulse-on duration; Pulse-off duration, RSM.

\section{Notation}

I : Supply current, A.

$\mathrm{T}(\mathrm{ON})$ : Pulse-on duration, unit.

T (OFF) : Pulse-off duration, unit.

MRR : Material removal rate,

EW : Volumetric electrode wear, \%

\section{Introduction}

Electrical Discharge Machining (EDM) is a nontraditional manufacturing process based on removing material from a part by means of a series of repeated electrical discharges (created by electric pulse generators at short intervals) between a tool, called electrode, and the part being machined in the presence of a dielectric fluid [1]. At present, EDM is a widespread technique used in industry for high-precision machining of all types of conductive materials such as metals, metallic alloys, graphite, or even some ceramic materials [2].

The process is a spark erosion method, eroding the workpiece by high frequency spark discharges [3]. EDM has a high capability of machining the accurate cavities of dies and molds. Nevertheless, electrode wear imposes high costs on manufacturers to substitute the eroded complicated electrodes by new ones for die making. In order to increase the machining efficiency, erosion of the workpiece must be maximized and that of the electrode minimized in EDM process [3]. Therefore, studying the electrode wear and related significant factors would be effective to enhance the machining productivity and process reliability.

*E-mail address: arindam2012@gmail.com

ISSN: 1791-2377 @ 2012 Kavala Institute of Technology. All rights reserved.
Various prediction methods can be applied to define the desired output variables through developing mathematical models to specify the relationship between the input parameters and output variables. The response surface methodology (RSM) is helpful in developing a suitable approximation for the true functional relationship between the independent variables and the response variable that may characterize the nature of the joints [4]. It has been proved by several researchers [5-8] that efficient use of statistical design of experimental techniques, allows development of an empirical methodology, to incorporate a scientific approach in the fusion welding procedure.

In the present investigation mathematical models, by using response surface methodology (RSM) have been generated to predict the effect of the process parameters of Electrical Discharge Machining (EDM) on material removal rate (MRR) and electrode wear (EW).

\section{Response Surface Methodology (RSM)}

Response surface methodology (RSM) is a collection of mathematical and statistical technique useful for analyzing problems in which several independent variables influence a dependent variable or response and the goal is to optimize the response [9]. In many experimental conditions, it is possible to represent independent factors in quantitative form as given in Eq. (1). Then these factors can be thought of as having a functional relationship or response as follows:

$\mathrm{Y}=\emptyset\left(\mathrm{x}_{1}, \mathrm{x}_{2}, \ldots \ldots, \mathrm{x}_{\mathrm{k}}\right) \pm \mathrm{e}_{\mathrm{r}}$

between the response $\mathrm{Y}$ and $\mathrm{x}_{1}, \mathrm{x}_{2}, \ldots, \mathrm{x}_{\mathrm{k}}$ of $\mathrm{k}$ quantitative factors, the function $\varnothing$ is called response surface or response function. The residual $\mathrm{e}_{\mathrm{r}}$ measures the experimental errors. 
For a given set of independent variables, a characteristic surface is responded. When the mathematical form of $\varnothing$ is not known, it can be approximate satisfactorily within the experimental region by polynomial.

In the practical application of RSM, it is necessary to develop an approximating model for the true response surface. The approximating model is based on observed data from the process or system and is an empirical model. Multiple regression is a collection of statistical techniques useful for building the types of empirical models required in RSM. Usually, a second-order polynomial Eq. (2) is used in RSM.

$$
Y=b_{0}+\sum_{j=1}^{k} b_{j} x_{j}+\sum_{j=1}^{k} b_{j j} x_{j}^{2}+\sum_{i<j} \sum_{j=2}^{k} b_{i j} x_{i} x_{j}
$$

where parameters $b_{i j}=0,1, \ldots, k$ are called the regression coefficients. In order to estimate the regression coefficients, a number of experimental design techniques are available. In this work, Box-Behnken design was used which fits the second order response surfaces very accurately. BoxBehnken designs provide relatively high quality predictions over the entire design space and do not require using points outside the original factor range. The upper limit of a factor was coded as +1 , and the lower limit was coded as -1 . The chosen levels of the selected process parameters with their units and notations are presented in Table 1.

Table 1. Important process parameters and their levels

\begin{tabular}{cccc}
\hline Factors & \multicolumn{3}{c}{ Levels } \\
\cline { 2 - 4 } & -1 & 0 & 1 \\
\hline $\mathrm{I}(\mathrm{A})$ & 3 & 7 & 11 \\
$\mathrm{~T}(\mathrm{ON})(\mu \mathrm{s})$ & 800 & 1000 & 1200 \\
$\mathrm{~T}(\mathrm{OFF})(\mu \mathrm{s})$ & 400 & 600 & 800 \\
\hline
\end{tabular}

\section{Experimental details}

\subsection{Electrode and work materials}

The electrode used in the present study was copper with a cross-sectional dimension of $18 \mathrm{~mm} \times 18 \mathrm{~mm}$. The major properties of the electrode materials are shown in Table 2 . The workpiece material used in the present study was mild steel. Their chemical compositions are shown in the Table 3.

Table 2. Major properties of electrode materials

\begin{tabular}{ccccc}
\hline $\begin{array}{c}\text { Electrode } \\
\text { material }\end{array}$ & $\begin{array}{c}\text { Thermal } \\
\text { conductivity } \\
\left(\mathbf{W} / \mathbf{m}-^{-} \mathbf{K}\right)\end{array}$ & $\begin{array}{c}\text { Melting } \\
\text { point } \\
\left({ }^{\circ} \mathbf{C}\right)\end{array}$ & $\begin{array}{c}\text { Electrical } \\
\text { resistivity } \\
(\mathbf{o h m}-\mathbf{c m})\end{array}$ & $\begin{array}{c}\text { Specific heat } \\
\text { capacity } \\
\left(\mathbf{J} / \mathbf{g}-^{-} \mathbf{C}\right)\end{array}$ \\
\hline Copper & 391 & 1083 & 1.69 & 0.385 \\
\hline
\end{tabular}

Table 3. Chemical composition of work metal

\begin{tabular}{ccccc}
\hline $\begin{array}{c}\text { Spacemen } \\
\text { number }\end{array}$ & \multicolumn{4}{c}{$\begin{array}{c}\text { Chemical composition (maximum } \\
\text { percentage) }\end{array}$} \\
\cline { 2 - 5 } & $\mathrm{C}$ & $\mathrm{S}$ & $\mathrm{P}$ & $\mathrm{Cu}$ \\
\hline IS: $226 / 75$ & 0.25 & 0.055 & 0.055 & 0.35 \\
\hline
\end{tabular}

\subsection{Experimental procedure}

The experimental work was conducted on a die sinking EDM machine of type SPARKONOX S 25 A. EDM oil was used as the dielectric fluid. The experimental setup is shown in Figure 1. During EDM experiments, the input parameters (factors) were current, T (ON) (pulse-on duration), T (OFF) (pulse-off duration). Square holes of dimensions $18 \mathrm{~mm} \times$ $18 \mathrm{~mm}$ were machined with a depth of $2.5 \mathrm{~mm}$. The volumes of the electrodes before and after machining gives the material removed from the electrode and the difference of volumes of the work before and after machining gives the material removed from the work. The electrode wear (EW) was calculated as the ratio of volume of material removed from the electrode to the same removed from the work [10]. Table 4 shows such material removal rate (MRR) values and volumetric electrode wear (EW) values for the samples.

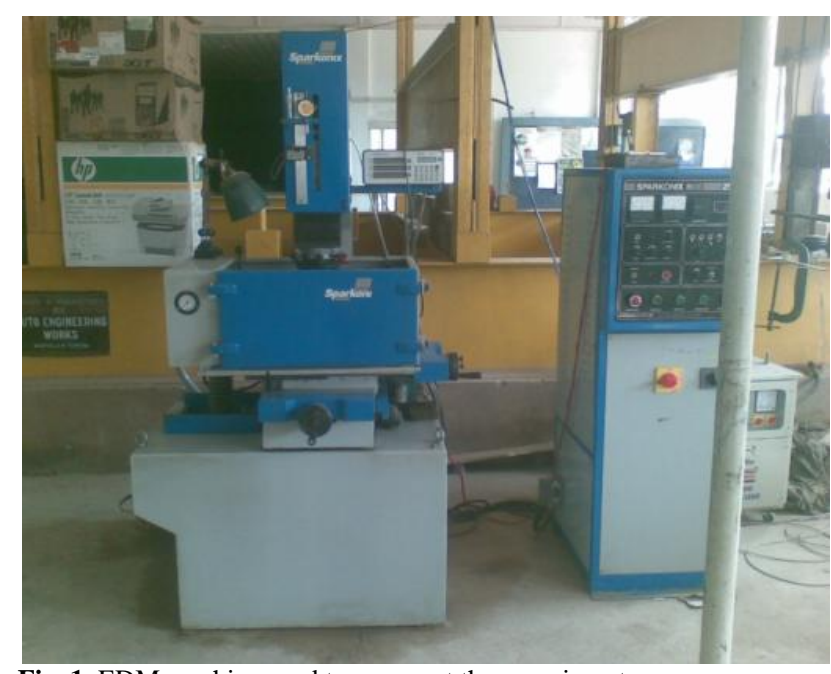

Fig. 1. EDM machine used to carry out the experiments.

Table 4. Design matrix and measured responses.

\begin{tabular}{|c|c|c|c|c|c|c|}
\hline Std & Run & $\begin{array}{c}\text { Supply } \\
\text { Current } \\
\text { I }\end{array}$ & $\begin{array}{c}\text { Pulse- } \\
\text { on } \\
\text { time } \\
\text { T } \\
(\text { ON })\end{array}$ & 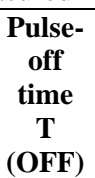 & $\begin{array}{c}\text { Material } \\
\text { Removal } \\
\text { Rate } \\
(\mathrm{MRR}), \\
\mathrm{mm}^{3} / \mathrm{min}\end{array}$ & $\begin{array}{c}\text { Volumetric } \\
\text { Electrode } \\
\text { Wear }(\text { EW), } \\
\%\end{array}$ \\
\hline 14 & 1 & 0 & 0 & 0 & 2.78 & 3.27 \\
\hline 9 & 2 & 0 & -1 & -1 & 11.61 & 3.023 \\
\hline 11 & 3 & 0 & -1 & 1 & 5.97 & 8.64 \\
\hline 6 & 4 & 1 & 0 & -1 & 6.144 & 2.59 \\
\hline 4 & 5 & 1 & 1 & 0 & 35.12 & 0.24 \\
\hline 16 & 6 & 0 & 0 & 0 & 2.78 & 3.27 \\
\hline 17 & 7 & 0 & 0 & 0 & 2.78 & 3.27 \\
\hline 12 & 8 & 0 & 1 & 1 & 5.38 & 0.59 \\
\hline 13 & 9 & 0 & 0 & 0 & 2.78 & 3.27 \\
\hline 8 & 10 & 1 & 0 & 1 & 4.57 & 6.41 \\
\hline 10 & 11 & 0 & 1 & -1 & 6.87 & 0.189 \\
\hline 3 & 12 & -1 & 1 & 0 & 0.533 & 6.92 \\
\hline 7 & 13 & -1 & 0 & 1 & 0.464 & 3.44 \\
\hline 5 & 14 & -1 & 0 & -1 & 1.06 & 0.42 \\
\hline 15 & 15 & 0 & 0 & 0 & 2.78 & 3.27 \\
\hline 1 & 16 & -1 & -1 & 0 & 1.004 & 1.69 \\
\hline 2 & 17 & 1 & -1 & 0 & 4.25 & 23.29 \\
\hline
\end{tabular}

\subsection{Development of mathematical models}

Design Expert statistical software package is used for analysis of measured responses and determining the mathematical models with best fit. The transformation of response that has been used to find the relation between material removal rate (MRR) and process parameters is Inverse Square Root. On the other hand Square Root has been used as the transformation of the response to predict 
the effect of process parameters on volumetric electrode wear (EWR). The final mathematical models thus obtained are shown in the Table 5 .

Table 5. Regression equations for the material removal rate and volumetric electrode wear during electric discharge machining

\begin{tabular}{lcl}
\hline $\begin{array}{l}\text { Sr. } \\
\text { No. }\end{array}$ & Response & $\begin{array}{l}\text { Regression equation } \\
\text { (In terms of Coded Factors) }\end{array}$ \\
\hline 1 & Material & $\frac{1}{\sqrt{(M R R)}}=0.60-0.41 \times I+0.021 \times$ \\
& Removal & $T(O N)+0.091 \times T(O F F)-0.17 \times$ \\
& Rate & $I \times T(O N)-0.11 \times I \times T(O F F)-$ \\
$($ MRR) & $0.017 \times T(O N) \times T(O F F)+0.30 \times$ \\
& & $I^{2}-0.15 \times T(O N)^{2}-0.074 \times$ \\
& & $T(O F F)^{2}$ \\
& Volumetric & $\sqrt{E W}=1.81+0.38 \times I-0.81 \times$ \\
& Electrode & $T(O N)+0.46 \times T(O F F)-1.42 \times$ \\
& Wear & $I \times T(O N)-0.071 \times I \times T(O F F)-$ \\
& $(E W)$ & $0.22 \times T(O N) \times T(O F F)+0.35 \times$ \\
& $I^{2}-0.16 \times T(O N)^{2}-0.49 \times$ \\
& $T(O F F)^{2}$ \\
\hline & &
\end{tabular}

\subsection{Checking Adequacy of the Model}

The adequacy of the models so developed was tested by using the analysis of variance technique (ANOVA). Using this technique, it was found that calculated F- ratios were larger than the tabulated values at a 95\% confidence level; hence, the models are considered to be adequate [11].

Two more criterions that are commonly used to illustrate the adequacy of a fitted regression model are the coefficient of determination $\left(\mathrm{R}^{2}\right)$. For the models developed, the calculated $\mathrm{R}^{2}$ and adjusted $\mathrm{R}^{2}$ values were above $80 \%$ and $70 \%$, respectively. These values indicate that the regression models are quite adequate [11]. The results of the ANOVA are given in Table 6 and Table 7.

Table 6. ANOVA analysis for the material removal rate (MRR) model

\begin{tabular}{|c|c|c|c|c|c|}
\hline Source & $\begin{array}{c}\text { Sum of } \\
\text { Squares }\end{array}$ & df & $\begin{array}{l}\text { Mean } \\
\text { Square }\end{array}$ & $\begin{array}{c}\text { F } \\
\text { Value }\end{array}$ & $\begin{array}{l}\text { p-value } \\
\text { Prob }>\text { F }\end{array}$ \\
\hline Model & 2.06 & 9 & 0.23 & 70.78 & $<0.0001$ significant \\
\hline$A-A$ & 1.35 & 1 & 1.35 & 417.01 & $<0.0001$ \\
\hline$B-B$ & $3.415 \mathrm{E}-3$ & 1 & $3.415 \mathrm{E}-3$ & 1.06 & 0.3379 \\
\hline$C-C$ & 0.066 & 1 & 0.066 & 20.43 & 0.0027 \\
\hline $\mathrm{AB}$ & 0.12 & 1 & 0.12 & 36.66 & 0.0005 \\
\hline $\mathrm{AC}$ & 0.047 & 1 & 0.047 & 14.48 & 0.0067 \\
\hline BC & $1.095 \mathrm{E}-3$ & 1 & $1.095 \mathrm{E}-3$ & 0.34 & 0.5786 \\
\hline$A^{2}$ & 0.38 & 1 & 0.38 & 119.09 & $<0.0001$ \\
\hline $\mathrm{B}^{2}$ & 0.090 & 1 & 0.090 & 28.02 & 0.0011 \\
\hline$C^{2}$ & 0.023 & 1 & 0.023 & 7.20 & 0.0314 \\
\hline Residual & 0.023 & 7 & $3.229 \mathrm{E}-3$ & & \\
\hline $\begin{array}{l}\text { Lack of } \\
\text { Fit }\end{array}$ & 0.023 & 3 & $7.534 \mathrm{E}-3$ & & \\
\hline Pure & 0.000 & 4 & 0.000 & & \\
\hline $\begin{array}{l}\text { Error } \\
\text { Cor Total }\end{array}$ & 2.08 & 16 & & & \\
\hline Std. Dev. & 0.057 & \multicolumn{3}{|c|}{ R-Squared } & 0.9891 \\
\hline Mean & 0.64 & \multicolumn{3}{|c|}{ Adj R-Squared } & 0.9752 \\
\hline C.V.\% & 8.91 & \multicolumn{3}{|c|}{ Pred R-Squared } & 0.8261 \\
\hline PRESS & 0.36 & \multicolumn{3}{|c|}{ Adeq R-Squared } & 28.522 \\
\hline
\end{tabular}

Table 7. ANOVA analysis for the volumetric electrode wear (EW) modal

\begin{tabular}{|c|c|c|c|c|c|}
\hline Source & $\begin{array}{c}\text { Sum of } \\
\text { Squares }\end{array}$ & df & $\begin{array}{c}\text { Mean } \\
\text { Square }\end{array}$ & $\begin{array}{c}\mathbf{F} \\
\text { Value }\end{array}$ & $\begin{array}{l}\text { p-value } \\
\text { Prob }>\text { F }\end{array}$ \\
\hline Model & 17.86 & 9 & 1.98 & 174.01 & $<0.0001$ significant \\
\hline$A-A$ & 1.14 & 1 & 1.14 & 100.19 & $<0.0001$ \\
\hline$B-B$ & 5.25 & 1 & 5.25 & 460.28 & $<0.0001$ \\
\hline$C-C$ & 1.68 & 1 & 1.68 & 147.06 & $<0.0001$ \\
\hline $\mathrm{AB}$ & 8.03 & 1 & 8.03 & 703.83 & $<0.0001$ \\
\hline $\mathrm{AC}$ & 0.020 & 1 & 0.020 & 1.77 & 0.2250 \\
\hline $\mathrm{BC}$ & 0.19 & 1 & 0.19 & 16.49 & 0.0048 \\
\hline$A^{2}$ & 0.51 & 1 & 0.51 & 44.46 & 0.0003 \\
\hline $\mathrm{B}^{2}$ & 0.10 & 1 & 0.10 & 9.02 & 0.0199 \\
\hline $\mathrm{C}^{2}$ & 1.03 & 1 & 1.03 & 90.22 & $<0.0001$ \\
\hline Residual & 0.080 & 7 & 0.011 & & \\
\hline $\begin{array}{l}\text { Lack of } \\
\text { Fit }\end{array}$ & 0.080 & 3 & 0.027 & & \\
\hline $\begin{array}{l}\text { Pure } \\
\text { Error }\end{array}$ & 0.000 & 4 & 0.000 & & \\
\hline $\begin{array}{l}\text { Cor } \\
\text { Total }\end{array}$ & 17.94 & 16 & & & \\
\hline Std. Dev. & 0.11 & \multicolumn{3}{|c|}{ R-Squared } & 0.9956 \\
\hline Mean & 1.81 & \multicolumn{3}{|c|}{ Adj R-Squared } & 0.9898 \\
\hline C.V.\% & 5.89 & \multicolumn{3}{|c|}{ Pred R-Squared } & 0.9288 \\
\hline PRESS & 1.28 & \multicolumn{3}{|c|}{ Adeq R-Squared } & 54.904 \\
\hline
\end{tabular}

The validity of regression models developed was further tested by drawing scatter diagrams. Typical scatter diagrams for material removal rate (MRR) and electrode wear (EW) are shown in Figures 2 and 3, respectively. The observed values and predicted values of the responses are scattered close to the $45^{\circ}$ line, indicating an almost perfect fit of the developed empirical models [12].

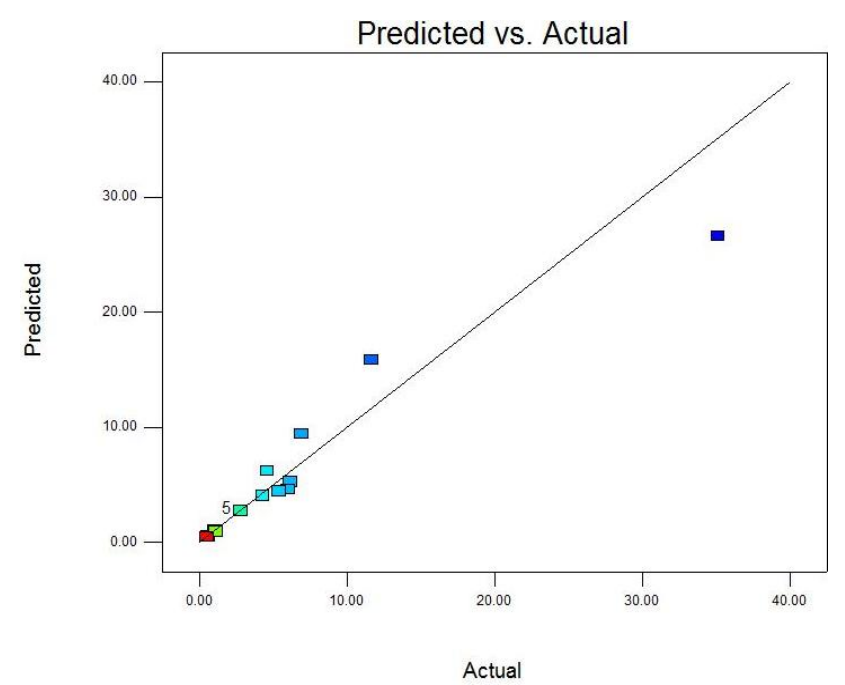

Fig. 2. Plot of actual vs. predicted response of material removal rate (MRR)

\section{Results and discussions}

\subsection{Effects of process parameters on the responses}

\subsubsection{Material Removal Rate (MRR)}

Figure 4 is a perturbation plot, which indicates the effect of all process parameters at the certain point in the design space. From this figure it is observed that the material 
removal rate (MRR) values increase, up to a certain value, and then MRR values decrease as the supply current values increase. This is expected because an increase in pulse current produce strong spark, which produces the higher temperature, causing more material to melt and erode from the work piece. On the other hand the low MRR at high pulse current region is considered to be related to inferior discharge due to insufficient cooling of work material. It is also observed from the figure that the MRR values decrease, up to a certain value, and then MRR values increase as the T (ON) values increase. While, in the case of the $T$ (OFF) values the result demonstrate that as the $\mathrm{T}$ (OFF) values increase the MRR values decrease, which is expected.

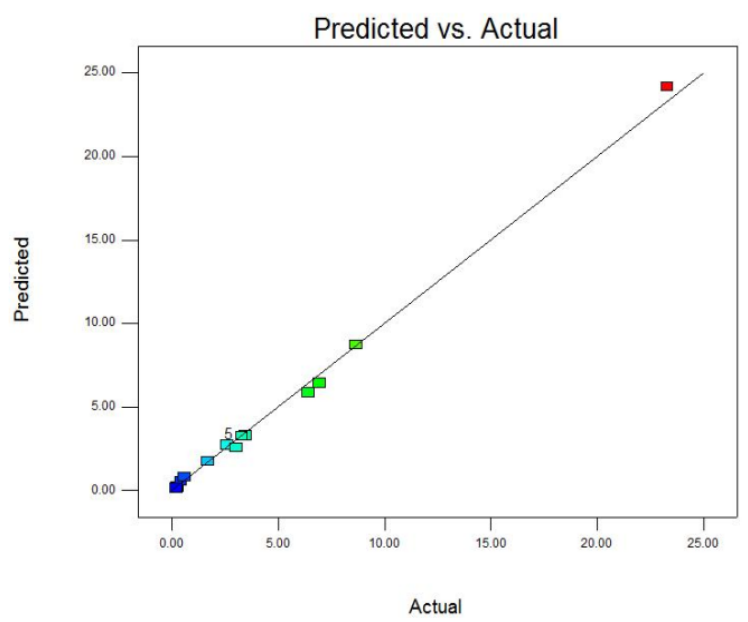

Fig. 3. Plot of actual vs. predicted response of volumetric electrode wear $(\mathrm{EW})$

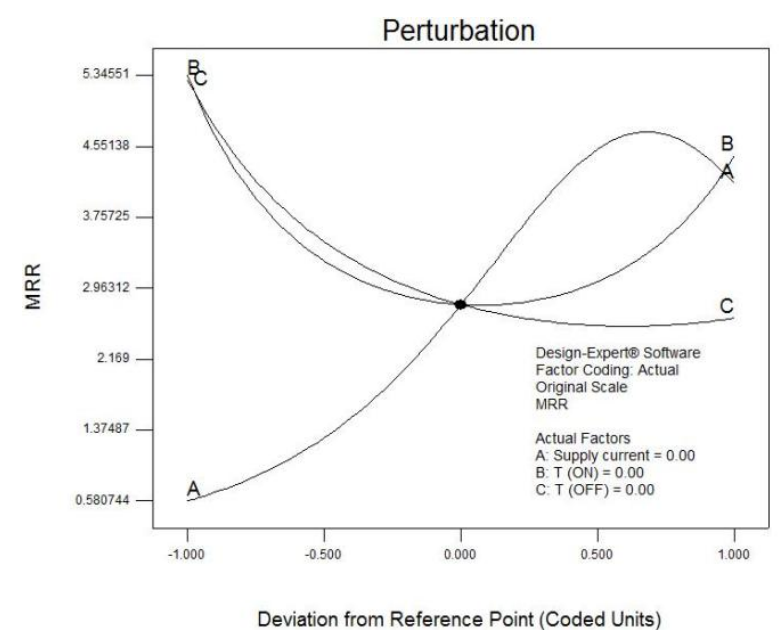

Fig. 4. Perturbation plot showing the effect of all factors on material removal rate (MRR)

\subsubsection{Volumetric Electrode Wear}

Figure 5 shows a perturbation plot to compare the effect of different machining factors at a particular point in the design space. From this figure, it can be noticed that the electrode wear (EW) increases as the supply current (I) increases. The result also demonstrated that the EW decreases as the $T$ $(\mathrm{ON})$ increases. Finally, the EWR values increase, up to a certain value and then EW values decrease as the $T$ (OFF) values increase.

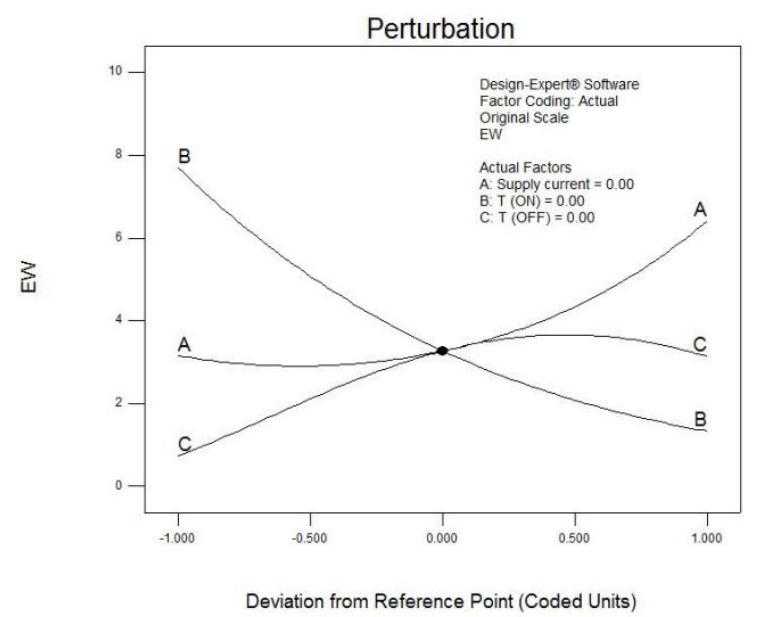

Fig. 5. Perturbation plot showing the effect of all factors on volumetric electrode wear (EW)

\section{Conclusions}

In this present work, regression equations of the polynomial type were calculated to predict the material removal rate (MRR) and electrode wear (EW) obtained during electric discharge machining (EDM). The prediction is for a particular value of machining parameter within the range studied. The finding also establishes that the effect of supply current (I) on material removal rate (MRR) is higher than the effect of other parameters of spark erosion machining. While in case of electrode wear (EW) the most influential factor was the intensity of the pulse-on time [T (ON)].

\section{Acknowledgements}

The author gratefully acknowledges the help of the Department of Mechanical Engineering, Welding Shop of National Institute of Technology, Agartala-799055, for their kind co-operation and help in this project.

\section{References}

1. Pandey, P.C., and Shah, H.S. (1980). Modern Machining Processes. New Delhi. Tata Mcgraw-Hill.

2. I. Puertas, C.J. Luis, J. Mater. Process. Technol. 143-144 (2003) 521-526.

3. C.C. Liu, Microstructure and tool electrode erosion in EDM of TiN/Si3N4 composites, Mater. Sci. Eng. J. 363 (2003) 221-227.

4. Grum J, Slabe J M.; "The use of factorial design and response surface methodology for fast determination of optimal heat treatment conditions of different Ni-Co-Mo surfaced layers", Journal of Materials Processing Technology, 2004, 155: 20262032.

5. Gunaraj. V, Murugan. N.; "Application of response surface methodology for predicting weld bead quality in submerged arc welding of pipes", Journal of Material Processing Technology, 
1999, 88: 266-275.

6. Manonmani. K, Murugan. N, Buvanasekaran. G.; "Effect of process parameters on the weld bead geometry of laser beam welded stainless steel sheets", Int J Joining Mater, 2005, 17(4): 103-109.

7. Balasubramanian. M, Jayabalan. V, Balasubramanian. V. "Developing mathematical models to predict tensile properties of pulsed current gas tungsten arc welded Ti-6Al-4V alloy", Materials and Design, 2008, 29(1): 92-97.

8. Palani. P. K, Murugan. N. "Optimization of weld bead geometry for stainless steel claddings deposited by FCAW", Journal of Materials Processing Technology, 2007, 190: 291-299.

9. Cochran, Cox. G. M. Experimental design [M]. New Delhi: Asia
Publishing House, 1962.

10. Puertas. I, Luis. C. J, Alvares. L;"Analysis of the influence of EDM parameters on surface quality, MRR and EW of WC-Co", Journal of Materials Processing Technology 153-154 (2004), pp: 1026-1032.

11. Ramasamy, S.; Gould, J.; and Workman, D. "Design of experiments study to examine the effect of polarity on stud welding." Welding Journal (v81, n2), (2002), pp: 19s-26s.

12. Kim. I.S.; Son, K.J.; Yang, Y.S.; and Yaragada, P.K.D.V."Sensitivity analysis for process parameters in GMA welding process using factorial design method." International Journal of Machine Tools \& Manufacture, vol: 43, (2003), pp763769. 